\title{
Vulnerability Resilience in the Major Watersheds of the Korean Peninsula
}

\author{
Yong Jung ${ }^{1}$, Daeun $\mathrm{Kim}^{2}$, Minha Choi ${ }^{3, *}$, Sangdan $\mathrm{Kim}^{4}$, and Moojong Park ${ }^{5}$ \\ ${ }^{I}$ Water Resources Research Division, Korea Institute of Construction Technology, Goyang, Republic of Korea \\ ${ }^{2}$ Department of Civil and Environmental Engineering, Hanyang University, Seoul, Republic of Korea \\ ${ }^{3}$ Water Resources and Remote Sensing Laboratory, Department of Water Resources, Graduate School of Water Resources, \\ Sungkyunkwan University, Suwon, Republic of Korea \\ ${ }^{4}$ Department of Environmental Engineering, Pukyong National University, Pusan, Republic of Korea \\ ${ }^{5}$ Department of Civil Engineering, Hanseo University, Seosan, Republic of Korea
}

Received 26 December 2013, revised 6 May 2014, accepted 12 June 2014

\begin{abstract}
Water resources management requires policy enforcement in a changing environment. Climate change must be considered in major watershed river restorations in Korea. The aim of river restorations is to provide better water resource control - now and in the future. To aid in policy making in the government sector, "vulnerability-resilience indexes" (VRIs) with a Delphi survey method have been adopted to provide a possible reference. The Delphi survey offers prioritized vulnerability proxy variables based on expert opinions regarding the changing environment in terms of climate change and river restorations. The VRIs of watersheds were improved after river restorations, with the exception of some locations. However, when climate change was taken into consideration in the analysis of conditions after the restorations were completed, the results showed that governments need to provide better mitigation strategies to increase vulnerability resilience in the face of climate change.
\end{abstract}

Key words: Vulnerability-resilience index, Delphi survey, Climate change, River restorations

Citation: Jung, Y., D. Kim, M. Choi, S. Kim, and M. Park, 2014: Vulnerability resilience in the major watersheds of the Korean Peninsula. Terr. Atmos. Ocean. Sci., 25, 857-868, doi: 10.3319/TAO.2014.06.12.01(Hy)

\section{INTRODUCTION}

To improve the current hazards in mitigation procedure implementation, an enforced policy should be provided based on new criteria developed in response to climate change (Füssel and Klein 2006). A diverse approach should be taken in the development of new mitigation criteria to include historical, statistical and sociological factors.

A "vulnerability index" can act as a reference for policy making and/or the evaluation of developing new criteria, because the practice of identifying and observing vulnerability may provide an improved understanding of effective strategies development for reducing hazards (Rygel et al. 2006). The United Nations Development Programme (Lim et al. 2005) defined vulnerability as the probability of exposure to shock and disturbance caused by disasters. Vulnerability has also been defined as the degree of damage after considering the ability to adapt to stresses, exposure and disturbances caused by outside forces (Kasperson et al. 2002). The In-

\footnotetext{
* Corresponding author

E-mail:mhchoi@skku.edu
}

tergovernmental Panel on Climate Change (McCarthy et al. 2001) classified vulnerabilities conceptually into exposure, sensitivity and adaptive capacity. Exposure and sensitivity convey the degree of contact and response to climate hazards. Adaptive capacity shows the capability for adjusting to given changes in climate. If the sensitivity value is higher than the adaptive capacity, vulnerabilities to climate change are increased. In the investigation of vulnerability to climate change, geographical, sociological, environmental and economic elements need to be considered (Rothman and Robinson 1997; Füssel and Klein 2006). Historical flood impacts, such as casualties and property damage and the probability of flooding associated with abnormal weather patterns can have geographical and environmental impacts. Moss et al. (2001) quantified vulnerability indices of climate change using proxy variables based on the conceptual classification of vulnerabilities and resilience, such as exposure, sensitivity and adaptive capacity to climate change. In their research, the "vulnerability-resilience indicator prototype" (VRIP) model was developed to collect climate change impacts 
on various sectors and populations and measure the future consequences of climate change. Based on the VRIP model, vulnerability-resilience indexes (VRIs) were generated to measure the magnitude of aggregate climate change impacts on the Korean Peninsula with an identical concept to the VRIP model (Yoo and Kim 2008). Several studies focused on the vulnerability attributable to climate change (Brooks et al. 2005; Eriksen and Kelly 2007). Vulnerability indicators were also applied to coastal (Balica et al. 2012) and agricultural areas (Iglesias et al. 1996; Füssel and Klein 2006) due to the impacts of climate change.

The Delphi survey method is a process that prioritizes proxy variables by implying weights on each proxy variable to present performance measures that accumulate data into usable information. Each proxy variable can be applied to a specific environment in a different way. The advantage of using a Delphi survey is the ability to obtain a consensus of expert opinions through a discussion process in an iterative opinion-sharing manner with a given problem. A Delphi survey was previously adopted to resolve water resource conflicts (Taylor and Ryder 2003) and to set up criteria for flood damage data collection (Elmer et al. 2010) and other research fields, such as education (Wicklein 1993; Okoli and Pawlowski 2004) and medicine (Kennedy 2004). Previously, Jung and Choi (2012) adopted a Delphi survey for climate issues and proposed that this could be outstanding means to develop more effective preparations to respond to climate change. In their research, prioritized vulnerability proxy variables for a small river basin were obtained and the degree of consensus for each categorized questionnaire was analyzed. However, after obtaining weights based on the priorities of the expert opinions, obtained through a Delphi survey, no real applications were performed.

The major purpose of this study was to investigate the applicability of VRIs using the Delphi survey method to deliver the strength of resilience of vulnerabilities attributed to changes in the environment, such as climate change and river restorations in major watersheds. VRIs based on proxy variables, prioritized through Delphi surveys, could be a valuable reference for the policy decision-making process.

\section{CLIMATE CHANGE AND RIVER RESTORATIONS}

In this study two major changes (climate change and river restorations in major watersheds) were considered to measure the vulnerabilities of the Korean peninsula. Climate change is an unavoidable issue for water resources. The Parry et al. (2007) reported that human activities generated more than $70 \%$ of total greenhouse gases during the 34 years between 1970 - 2004. These greenhouse gases can cause increases in air temperature, melt water, and sea level, and as a consequence, more convection around the equator, which induces more rainfall and unexpected storms. Based on these influences, the Korean government has performed river restorations for major watersheds to help enforce water security, flood control, and ecosystem vitality. The Korean peninsula consists of major watersheds along major rivers (the Han, Nakdong, Geum, and Youngsan Rivers; Fig. 1).

\section{VULNERABILITY AND DELPHI SURVEY METHOD}

Based on Moss et al. (2001), an additional class of vulnerability on climate change was added in this research. In addition, the proxy variables generated by Moss et al. (2001) were modified to make them applicable to the context of the Korean Peninsula with respect to the hydrological and sociological impacts on life. All proxy variables categorized by the three classes required normalization because the proxy variables had diverse units. The dimension index methods used in UNDP (2006) were applied for normalization. Proxy variables in each category may have different impacts on a specific condition; thus, the Delphi survey is used as a prioritizing function to provide specific information on different conditions.

The procedure to develop VRIs was as follows: (1) generate normalized proxy variables, (2) apply weights based on the priorities in terms of dependency on climate change, (3) calculate total values in each category, and (4) produce the VRIs. Equation (1) presents the dimension index with

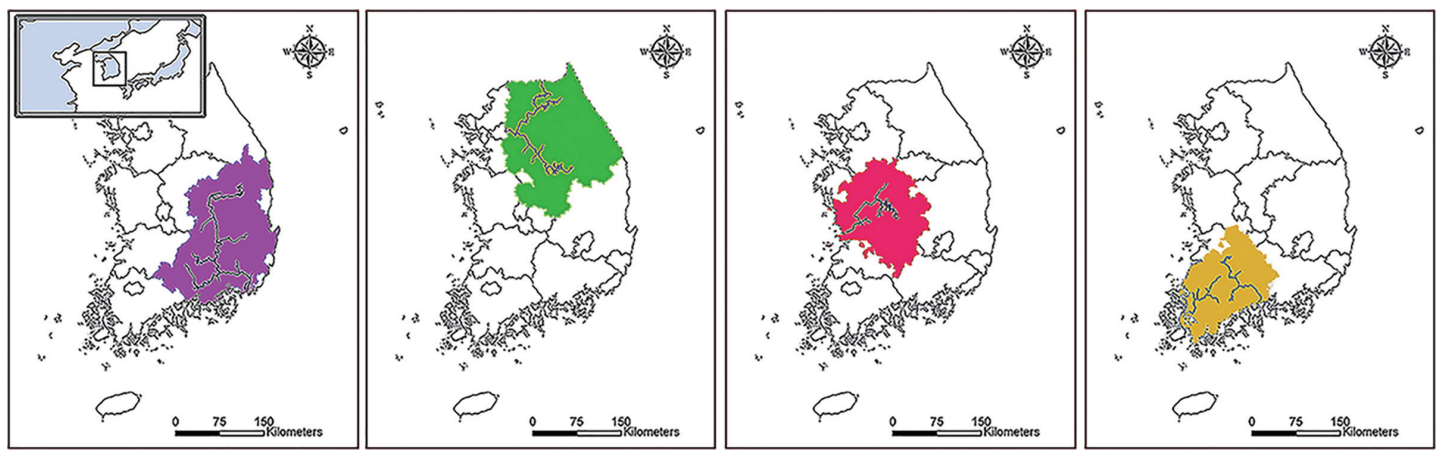

Fig. 1. The four major watersheds of the Korean Peninsula. 
normalization and Eqs. (2), (3), and (5) show the weighted scores for each sector for VRIs. Potential impact score Eq. (4) presents the negative influence on VRIs Eq. (6).

Dimension index:

$y_{i j}=\frac{x_{i j}-x_{j \min }}{x_{j \max }-x_{j \min }}$

Exposure score:

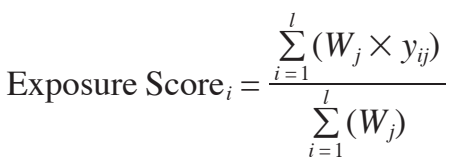

Sensitivity score:

Sensitiviity Score $_{i}=\frac{\sum_{i=1}^{m}\left(W_{j} \times y_{i j}\right)}{\sum_{i=1}^{m}\left(W_{j}\right)}$

Potential impact score:

Potential Impact Score $_{i}=$

$\left(\right.$ Exposure Score $_{i}+$ Sensitivity Score $\left._{i}\right) / 2$

Adaptation score:

Adaptation Score $_{i}=\frac{\sum_{i=1}^{n}\left(W_{j} \times y_{i j}\right)}{\sum_{i=1}^{n}\left(W_{j}\right)}$

Vulnerability-resilience index (VRI):

$\mathrm{VRI}_{i}=\left(\right.$ Adaptation Score $_{i}-$ Potential Impact Score $\left._{i}\right) / 2$

where

$y_{i j}$ : normalized $j^{\text {th }}$ proxy variable at $i^{\text {th }}$ grid.

$x_{i j}: \dot{j}^{\text {th }}$ proxy variable at $i^{\text {th }}$ grid.

$x_{j \max }$ : a maximum value from all grids of $j^{\text {th }}$ proxy variable.

$x_{\text {jmin }}$ : a minimum value from all grids of $j^{\text {th }}$ proxy variable.

$W_{j}$ : weight for $j^{\text {th }}$ proxy variable.

$l$ : total number of proxy variables in Exposure.

$m$ : total number of proxy variables in Sensitivity.

$n$ : total number of proxy variables in Adaptation.

The proxy variables in Table 1 were selected from previous studies (Jung and Choi 2012), and classified into three categories based on the size of the impact and data availability (exposure, sensitivity, and adaptive capacity). The first and second items for exposure were obtained from historical records from the Korea Meteorological Administration (KMA). The number of days with $>150 \mathrm{~mm}$ rainfall over a period of 30 years $(1981$ - 2010) were counted at each rainfall observation location and the average number of dates over 30 years were kriged to obtain grid data. Ordinary kriging with an exponential model embedded in ArcGIS was used for the kriging process. Property and population densities were obtained from annual statistical reports on real estate and population, respectively. The purpose of selecting the item 'People over 61 years and less than 15 years' was that these people have limitations in handling the difficulties caused by heavy rainfall. For sensitivity, geographical and historical items were major components. Geographical information, such as river length and town area, was obtained from the Water Management Information System (WAMIS) of the Korean government. Historical flood damage amounts were obtained from annual disaster reports from $1994-2010$. The slopes of watersheds were taken directly from the $1 \times 1 \mathrm{~km}$ digital elevation model generated in 2000. Adaptive capacity describes the capability for adaptation to changes in the environment caused by climate change. Most of the variables were from annual governmental statistical reports with the exception of 'Prevention results of local government' and 'Hazard mitigation system,' which were from survey reports from the National Emergency Management Agency.

Diverse climate change scenarios, including A2, A1B, and B1, were adopted and assembled for this study to evaluate future vulnerability to climate change. For the generation of future scenarios, future population, economic status, governance, social values and changes in technology were considered. We selected the CNCM3 model from the 24 Global Circulation Models (GCMs) created by the IPCC Data Distribution Center (DDC), because this model has been suggested to be the most appropriate model for the Korean peninsula (Kyoung 2010).

A Delphi survey was used as a prioritizing function to give different weights to proxy variables. A Delphi survey is an iterative survey method that shares participants' opinions anonymously. Participants can thus recognize priorities that they did not previously consider. All participants are experts on the given subject. Through a Delphi survey, some agreement in expert opinion of the given problem can be expected using the iterative opinion sharing system.

\section{RESULTS AND DISCUSSION}

\subsection{Delphi Survey}

For this study, two Delphi surveys were performed, on 12 January and 15 March 2012, with 2-week time periods for each. The 26 selected experts were researchers with either a master's or a Ph.D. degree in water resources who were working at research institutes. Figure 2 shows the weights of each proxy variable from the first and second Delphi surveys. The sum of total weights for each classification is one. In the Delphi survey completion process experts expressed 
their own opinions based on their own criteria and provided weights for each proxy variable. For exposure, the first proxy variable, the number of dates with over $150 \mathrm{~mm}$ rainfall per day obtained the maximum weight with minimum changes through the Delphi survey. The weight of population density in exposure was decreased substantially compared with the other proxy values. Based on the experts' opinions, s1 (river length) had a minimum weight because river length will be minimally affected by restorations of major watersheds and/or climate change. The weights of other proxy variables of sensitivity were distributed around 0.15 , with slight changes in the given weights from the two Delphi surveys.
Adaptive capacity had large differences in weight between proxy variables. A4 (number of government employees) and A6 (hazard mitigation system) had minimum and maximum weights for adaptive capacity, respectively.

The size of variance shown in Fig. 3 may indicate the priority of a given proxy variable. When the variance size is smaller than those of other variables, this proxy variable can have a higher weight for the given criteria (changing environment impacts) because all experts think this proxy variable may have a higher influence on vulnerability attributable to climate change. Exposure 1 (number of dates with over $150 \mathrm{~mm}$ rainfall per day), Sensitivity 4 (town area

Table 1. Categorized proxy variables used in the VRI.

\begin{tabular}{|c|c|c|}
\hline \multicolumn{2}{|l|}{ Classification } & Proxy Variables \\
\hline \multirow{5}{*}{ Exposure } & 1 & Number of days over 150 mm rainfall per day (days) \\
\hline & 2 & Daily rainfall probability of 100 years storm $(\mathrm{mm})$ \\
\hline & 3 & Property density $\left(\$ \mathrm{~m}^{-2}\right)$ \\
\hline & 4 & Number of people over 61 and less than 15 years old (persons) \\
\hline & 5 & Population density (persons $\mathrm{km}^{-2}$ ) \\
\hline \multirow{7}{*}{ Sensitivity } & 1 & River length (km) \\
\hline & 2 & Water level changes at the connection of main stream and tributaries $\left(\mathrm{km}^{2}\right.$ or m $\left.\mathrm{m}^{2}\right)$ \\
\hline & 3 & Effective area of backwater from newly installed dams $\left(\mathrm{km}^{2}\right.$ or $\left.\mathrm{m}^{2}\right)$ \\
\hline & 4 & Town area near river $\left(\mathrm{m}^{2}\right)$ \\
\hline & 5 & Area rate of un-refurbished area $(\%)$ \\
\hline & 6 & Historical flood damage amount $(\$)$ \\
\hline & 7 & Slope of watershed $(\%)$ \\
\hline \multirow{6}{*}{ Adaptive Capacity } & 1 & Sewer ratio $(\%)$ \\
\hline & 2 & Prevention results of local governments $(\%)$ \\
\hline & 3 & Financial independence $(\%)$ \\
\hline & 4 & Number of government employees (persons) \\
\hline & 5 & Number of hospital per million people (hospitals/million persons) \\
\hline & 6 & Hazard mitigation system $(\%)$ \\
\hline
\end{tabular}

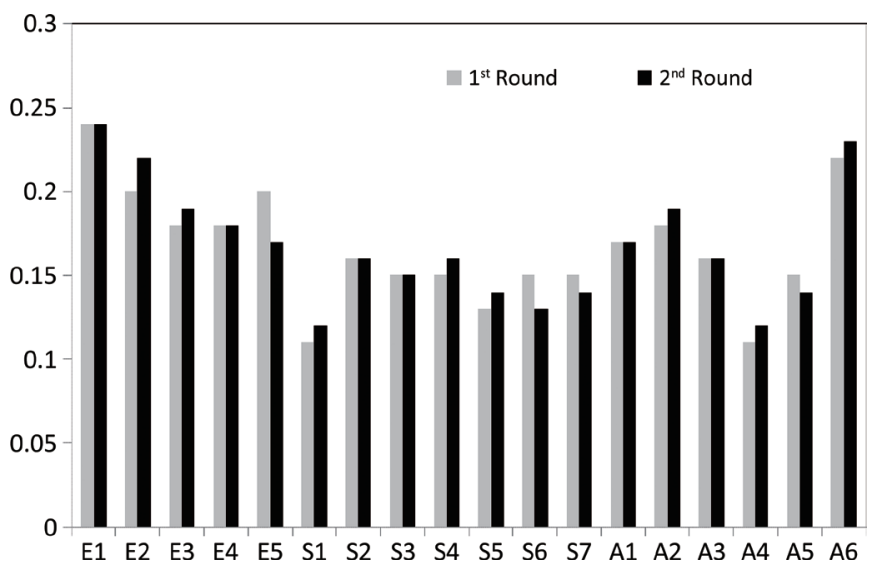

Fig. 2. Averaged weights of the proxy variables from the Delphi survey (E: exposure, S: sensitivity, A: adaptive capacity). 

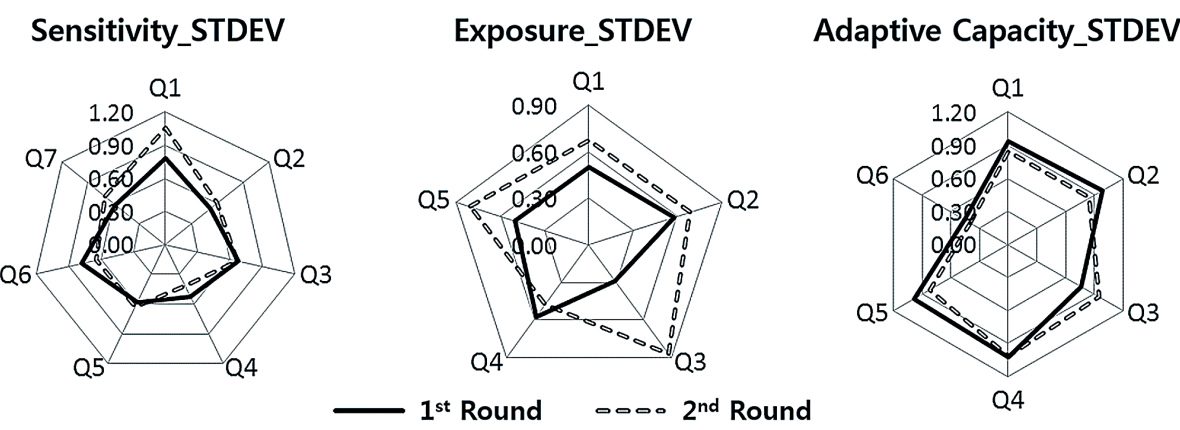

Fig. 3. Variances in responses to each questionnaire for the first and second Delphi surveys.

near river) and Adaptive Capacity 6 (hazard mitigation system) had the maximum weights, with minimal variances of $0.63,0.42$, and 0.45 , respectively. On the other hand, river length in Sensitivity 1 and the number of government employees in Adaptive Capacity 4 had the lowest weights in both surveys, and both categories had the highest variances.

Table 2 displays the list of ranks for each class from the two Delphi surveys. To validate the central tendency of rank variance for an individual proxy variable and opinion concurrence of participants' significant rankings in the decision, rank variance $\left(D^{2}\right)$ and Kendall's W were used, respectively, as described by Jung and Choi (2012). Exposure 2 (daily rainfall probability of a 100-year storm) showed the highest increase in rank variance in this category. Exposures 1,3, and 4 had slightly increased rank variances, too. Conversely, reduced rank variance was found in Exposure 5 (population density).

The most sensitive proxy variables displayed a reduced central tendency in rank variances with the exception of Sensitivities 4 and 5. Thus, no opinion consensus was achieved for sensitivity from these two iterations, as indicated by the reduced Kendall's W. Proxy variables for the adaptive characteristic of resilience indicators provided more than moderate agreement for both Delphi surveys with a fair confidence in rankings. Exposure showed an increased W score, from 0.29 - 0.39. Based on these results, prioritized proxy variables with a given weight were finalized to create a vulnerability-resilience index.

\subsection{Vulnerability-Resilience Index}

After obtaining weights for the proxy variables, VRIs were generated based on the following four cases: case 1, previous situation (no restorations, no climate change); case 2, restorations without climate change (restorations, no climate change); case 3 , no restorations with climate change (no restorations, climate change); case 4 , both (restorations, climate change).

Figures $4 \mathrm{a}-\mathrm{d}$ show the VRIs for each grid $(1 \times 1 \mathrm{~km})$ with a scale of -0.4 to +0.4 . If a VRI is close to -0.4 , this means the location has minimum resilience to environmental changes caused by climate change. Dark lines represent the main stream of the river. In the case of no consideration for restorations or climate change (case 1), the four distinguished sectors showed minimum vulnerability resilience (red and orange colors). For case 2, minor changes in VRIs were seen in any of the locations after restorations of the major watersheds. When we considered climate change (case 3), points along the upper stream in the southern area became worse, as shown by the increase in the number of red grids, and some grids changed from yellow (0 to -0.05$)$ to orange $(-0.05$ to -0.10$)$. An increase in the number of yellow grids in the northern region appeared after climate change was considered. To compensate for the influences of climate change, restorations of the major watersheds were included in the evaluation (case 4). The VRI grids for case 4 show that no substantial change was found when compared with the VRIs for case 3. Subtractions of the VRIs between the two conditions are shown in Figs. $4 \mathrm{e}-\mathrm{g}$.

Figures $4 \mathrm{e}-\mathrm{g}$ show the VRI differences between cases 2 and 1, cases 3 and 1, and cases 4 and 1, respectively. As shown in Fig. 4e, VRIs were improved, except in some isolated locations along the main stream, plotted in red. The locations with worsened VRIs had a higher sensitivity watershed slope. Northern parts of the upstream area showed substantial improvement in VRIs, shown in dark green. Most of the area showed minimal influences from the restorations of the major watersheds (light green color). Downstream areas on the east and west sides in the southern part of Nakdong River showed VRI improvement. When only climate change was considered, without restorations, as shown in Fig. 4f, some areas near the main stream of the river worsened. The center of the southern part of the Nakdong River basin showed the worst VRI distribution, shown in red. The upstream starting point showed substantial changes in VRIs. All of the watershed was influenced substantially by climate change. Considering both conditions shown in Fig. $4 \mathrm{~g}$, the restorations did not seem strong enough to overcome or reduce the vulnerabilities caused by climate change. However, the central upstream area showed improvements in VRIs, as shown by the green spots.

Figures $5 \mathrm{a}-\mathrm{d}$ show the VRIs of various factors in the Han River basin. Without considering climate change or the 
restorations (case 1), the southeast part of the Han River basin had minimal VRIs, with orange grids and some red grid points. This location was not substantially impacted by the restorations of the major watersheds because the location of this area is a small distance from the main stream of the Han River. When considering the effects of restorations (case 2), the VRIs at each grid showed minor differences from case 1. Case 3 showed considerable changes, with darker to lighter greens and more yellow areas, as seen in the case of the Nakdong River basin. The VRIs for case 4 were very close to those of case 3 . That is, the restorations of the major watersheds might require enforced or improved policies to overcome the climate effects.

Figure 5e shows a slight improvement in VRIs caused by the restorations with darker green areas in the middle of the main stream of the Han River. For hazard mitigation some grid points, shown in red, near the improved VRI areas will require more consideration to minimize the damage from climate hazards even after the restorations. The major watershed restorations decreased vulnerabilities under current conditions; however, with climate change, these restorations did not show any significant impacts on the Nakdong River basin in terms of vulnerabilities (Fig. $5 \mathrm{~g}$ ).

The Geum River basin showed more vulnerable areas, showing red grids after considering climate change, indicating that these regions still require more attention in terms of hazard mitigation. As seen in Fig. 6b, essential VRI improvements did not appear in the Han River after the restorations were completed. That is, these restorations will not produce results in terms of flood mitigation, even in the current environment. After including climate change the number of highly vulnerable locations increased, as shown by the red grids located in the upper east and lower west side. Worsened areas can also be seen, with their colors changing from green to yellow in the southern and upper middle regions. The final generation of the VRI map, considering both conditions, displayed

Table 2. List of ranks for exposure, sensitivity, and adaptive capacity in the first and second Delphi Surveys.

\begin{tabular}{|c|c|c|c|c|c|}
\hline & \multirow{2}{*}{ Issue number } & \multicolumn{2}{|c|}{ Round 1} & \multicolumn{2}{|c|}{ Round 2} \\
\hline & & Mean Rank & $D^{2}$ & Mean Rank & $D^{2}$ \\
\hline \multirow{7}{*}{ Exposure } & 1 & 1.40 & 2.56 & 1.33 & 2.78 \\
\hline & 2 & 2.60 & 0.16 & 2.13 & 0.75 \\
\hline & 3 & 3.00 & 0.00 & 2.80 & 0.04 \\
\hline & 4 & 3.13 & 0.02 & 3.47 & 0.22 \\
\hline & 5 & 2.60 & 0.16 & 3.28 & 0.07 \\
\hline & Totals & 12.73 & & 13.00 & \\
\hline & & $\begin{array}{c}\mathrm{W} \\
0.29\end{array}$ & & $\begin{array}{c}\mathrm{W} \\
0.39\end{array}$ & \\
\hline \multirow{9}{*}{ Sensitivity } & 1 & 4.73 & 0.54 & 4.33 & 0.11 \\
\hline & 2 & 2.07 & 3.74 & 2.27 & 3.00 \\
\hline & 3 & 2.60 & 1.96 & 3.40 & 0.36 \\
\hline & 4 & 2.60 & 1.96 & 2.33 & 2.78 \\
\hline & 5 & 3.93 & 0.00 & 3.87 & 0.02 \\
\hline & 6 & 3.20 & 0.64 & 4.13 & 0.02 \\
\hline & 7 & 3.07 & 0.87 & 3.07 & 0.87 \\
\hline & Totals & 22.20 & & 23.40 & \\
\hline & & $\begin{array}{c}\mathrm{W} \\
0.32\end{array}$ & & $\begin{array}{c}\mathrm{W} \\
0.22\end{array}$ & \\
\hline \multirow{8}{*}{ Adaptive Capacity } & 1 & 3.00 & 0.25 & 2.87 & 0.40 \\
\hline & 2 & 2.13 & 1.87 & 2.27 & 1.52 \\
\hline & 3 & 3.07 & 0.19 & 3.07 & 0.19 \\
\hline & 4 & 4.60 & 1.21 & 4.53 & 1.07 \\
\hline & 5 & 3.67 & 0.03 & 4.13 & 0.40 \\
\hline & 6 & 1.13 & 5.60 & 1.20 & 5.29 \\
\hline & Totals & 17.60 & & 18.07 & \\
\hline & & $\begin{array}{c}\mathrm{W} \\
0.52\end{array}$ & & $\begin{array}{c}\text { W } \\
0.51\end{array}$ & \\
\hline
\end{tabular}


(a)

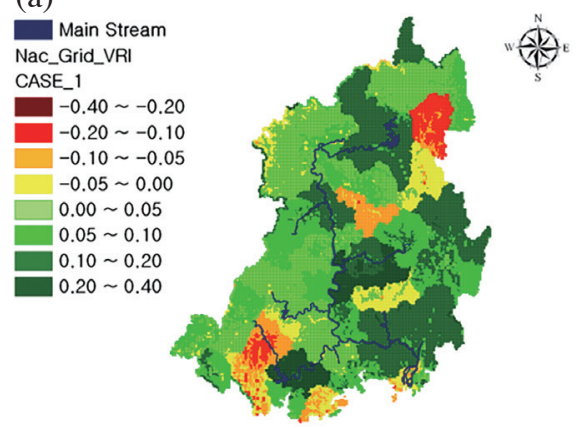

(c)

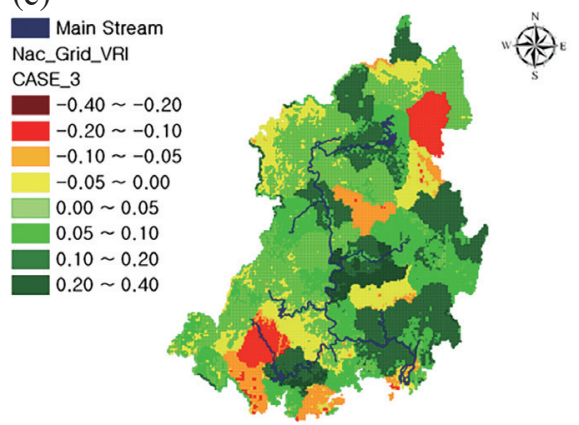

(e)

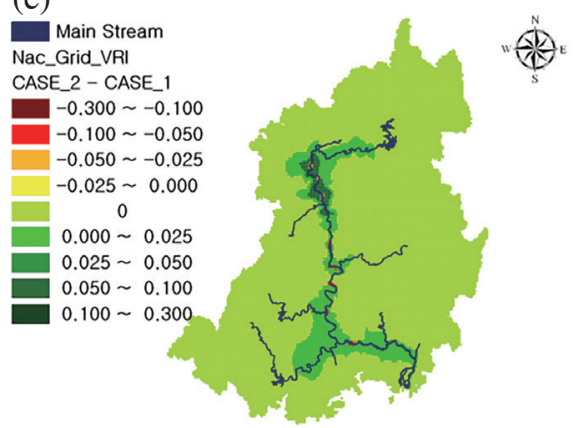

(g)

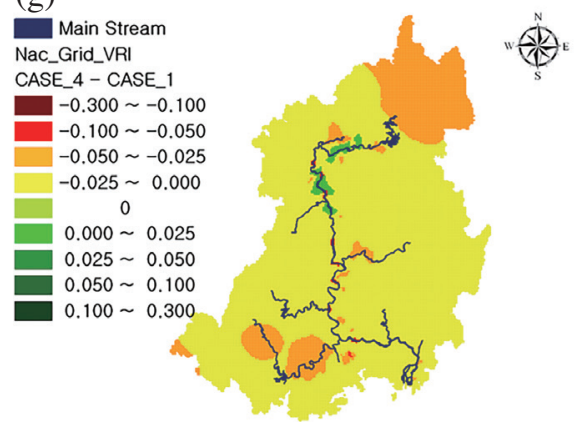

(b)

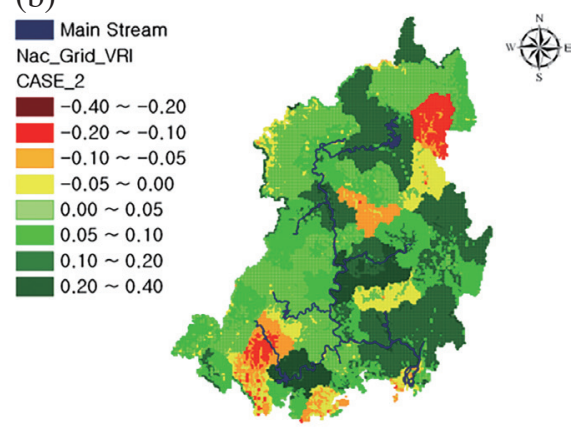

(d)

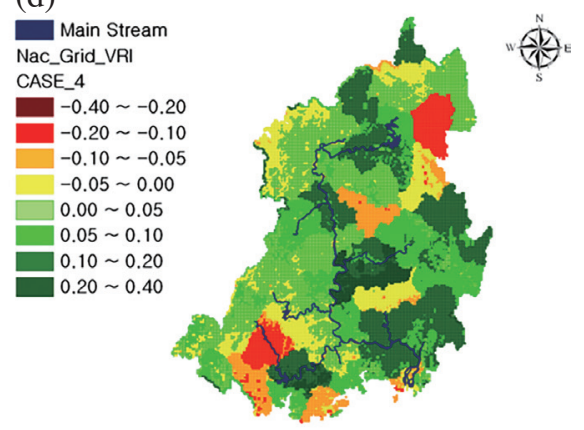

(f)

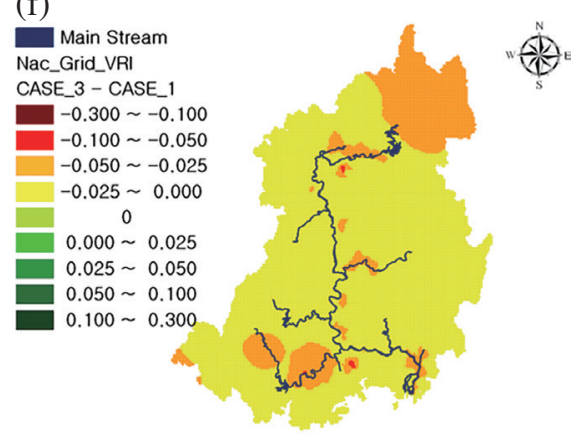

Fig. 4. Vulnerability-resilience index map of the Nakdong River basin for the four cases (a - d): case 1 (w/o restorations, w/o climate change), case 2 (w/ restorations, w/o climate change), case 3 (w/o restorations, w/ climate change), and case 4 (w/ restorations, w/ climate change), and VRI changes based on the status of the Nakdong River basin $(\mathrm{e}-\mathrm{g})$. 
(a)

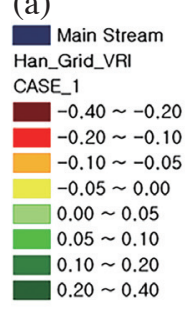

(c)

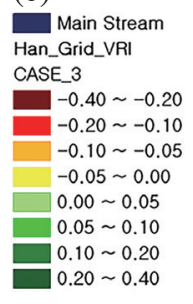

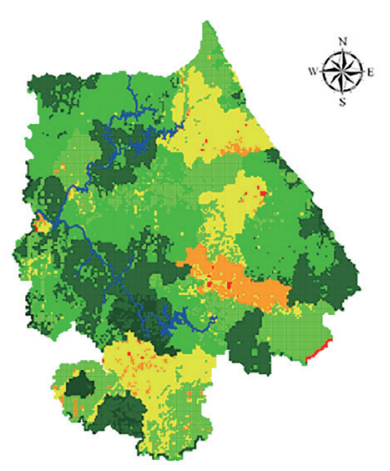

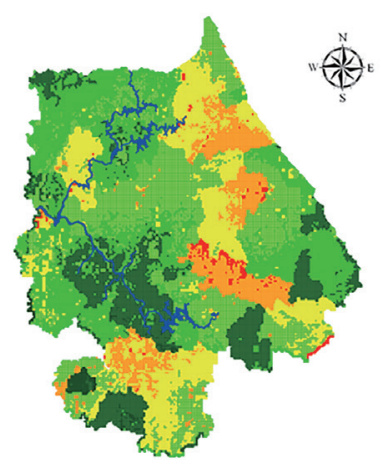

(d)

Main Stream Han_Grid_VRI
CASE_4
$-0.40 \sim-0.20$ $-0.20 \sim-0.10$ $-0.10 \sim-0.05$ $-0.05 \sim 0.00$ $0.00 \sim 0.05$ $0.00 \sim 0.05$
$0.05 \sim 0.10$
$0.10 \sim 0.20$ $0.10 \sim 0.20$
$0.20 \sim 0.40$ $0.20 \sim 0.40$
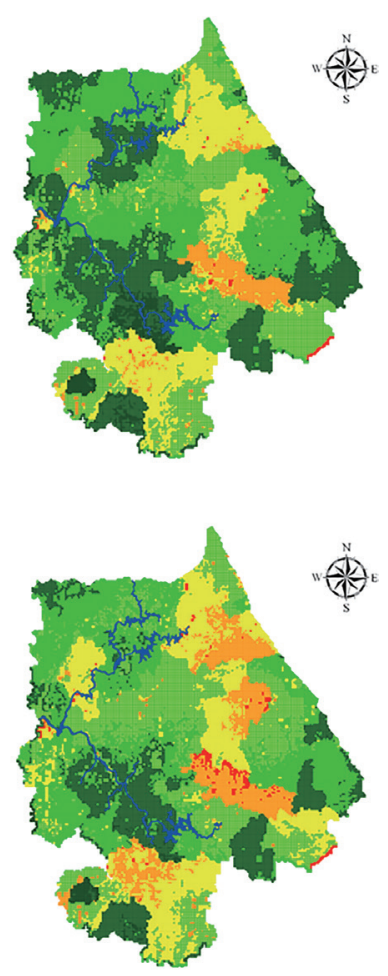

(e)

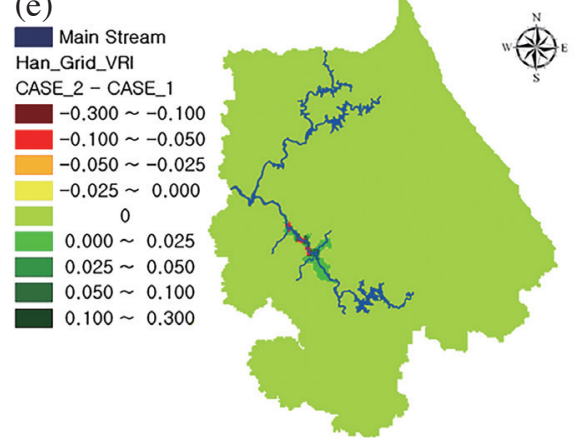

(g)

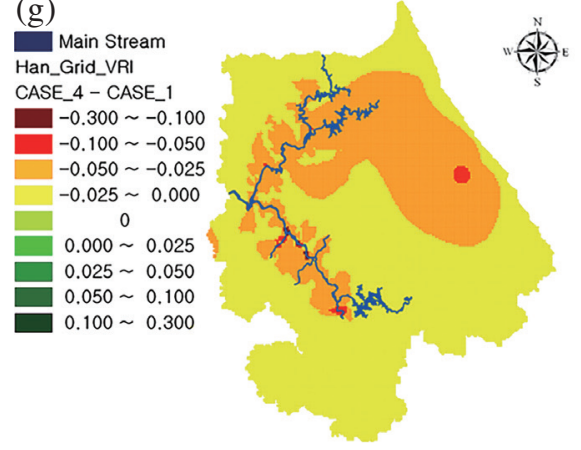

(f)

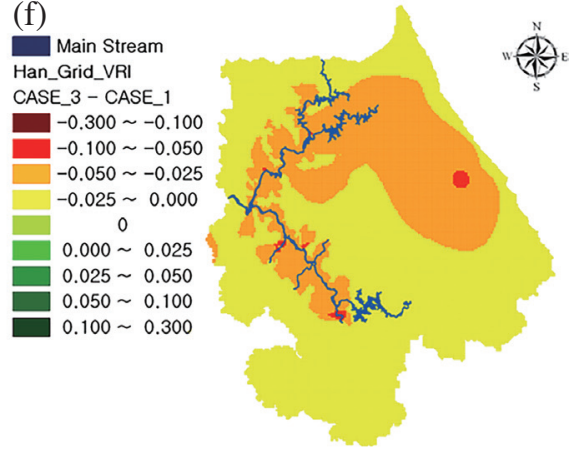

Fig. 5. Vulnerability-resilience index map of the Han River basin for the four cases (a - d): case 1 (w/o restorations, w/o climate change), case 2 (w/ restorations, w/o climate change), case 3 (w/o restorations, w/ climate change), and case 4 (w/ restorations, w/ climate change), and VRI changes based on the status of the Han River basin $(\mathrm{e}-\mathrm{g})$. 
(a)

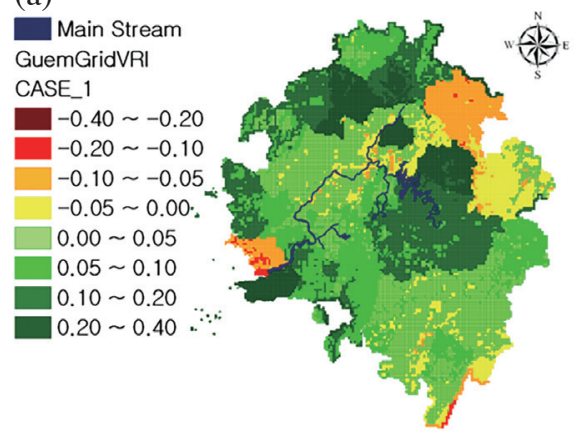

(c)

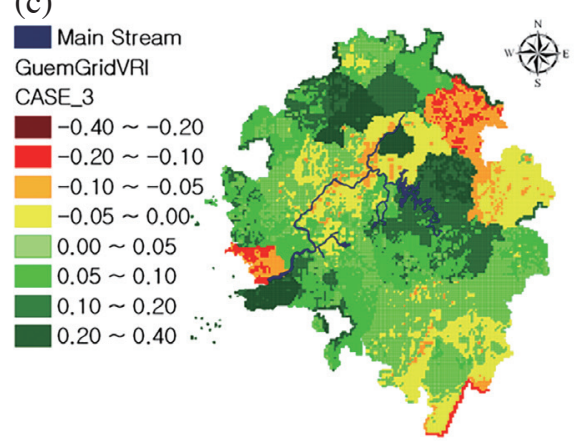

(e)

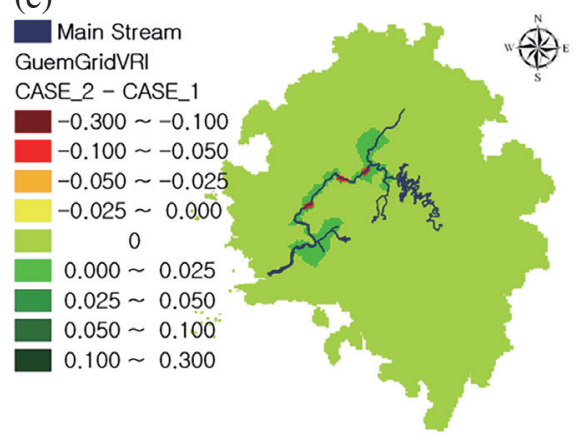

(g)

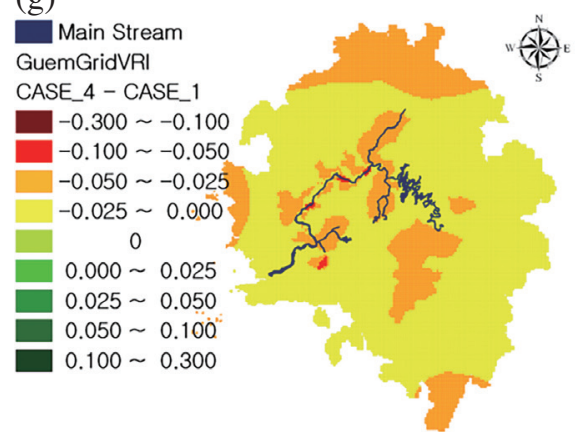

(b)

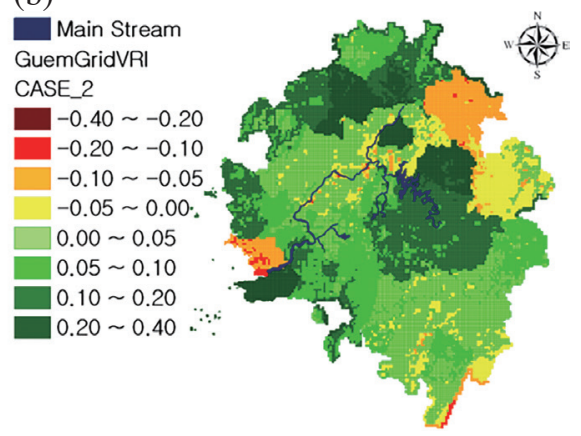

(d)

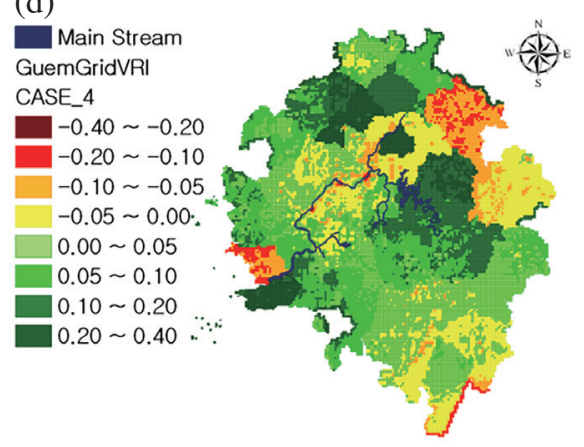

(f)

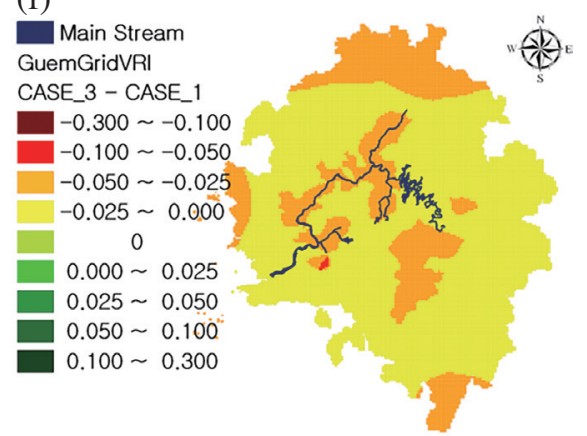

Fig. 6. Vulnerability-resilience index map of the Geum River basin for the four cases (a - d): case 1 (w/o restorations, w/o climate change), case 2 (w/ restorations, w/o climate change), case 3 (w/o restorations, w/ climate change), and case 4 (w/ restorations, w/ climate change), and VRI changes based on the status of the Geum River basin $(\mathrm{e}-\mathrm{g})$. 
a mixture of worsened vulnerabilities. Figures $6 \mathrm{e}-\mathrm{g}$ show results similar to those found based on the maps in Figs. $6 \mathrm{a}-\mathrm{d}$. The restorations had positive impacts around the main river stream, as seen in Fig. 6e. However, Fig. $6 \mathrm{~g}$ shows the worst conditions in terms of the VRIs of all grid points after the restorations, even including the main stream area.

For the Youngsan River basin region (Fig. 7a), current vulnerable resilience without the inclusion of either condition was low compared with the other river basins. However, even after river restorations were completed, (a)

Main Stream
YS_Grid_VRI
CASE_1
$-0.40 \sim-0.20$
$-0.20 \sim-0.10$
$-0.10 \sim-0.05$
$-0.05 \sim 0.00$
$0.00 \sim 0.05$
$0.05 \sim 0.10$
$0.10 \sim 0.20$
$0.20 \sim 0.40$

(c)

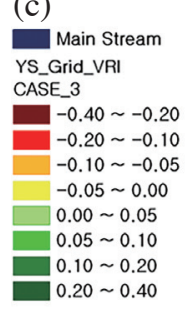

(e)
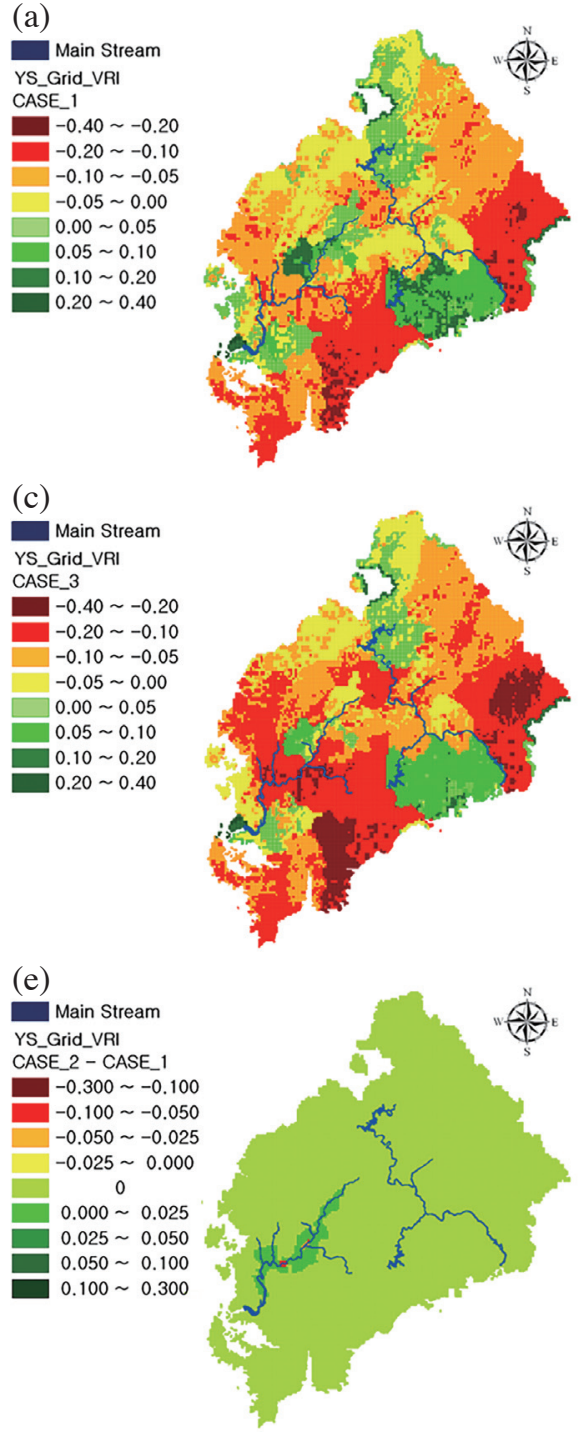

(g)

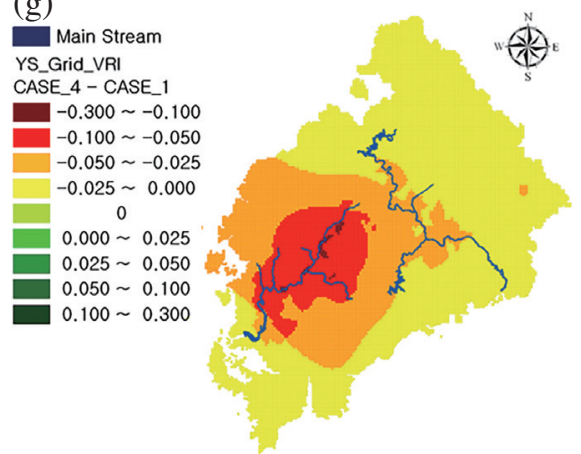

(b)

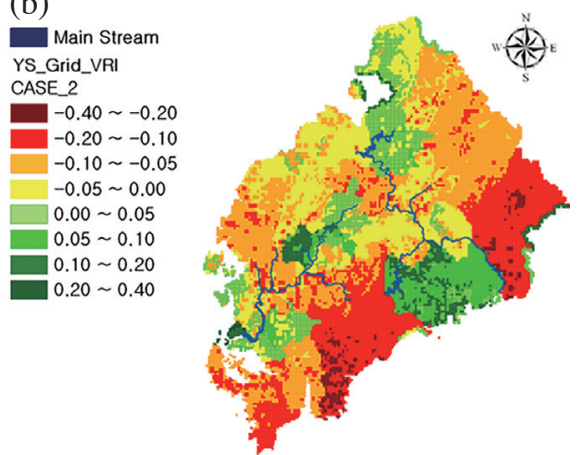

(d)

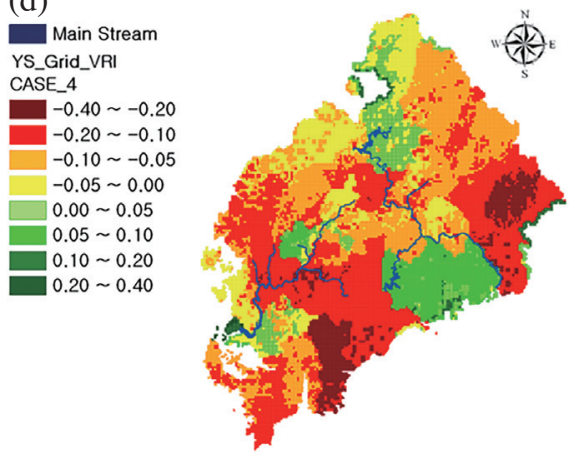

(f)

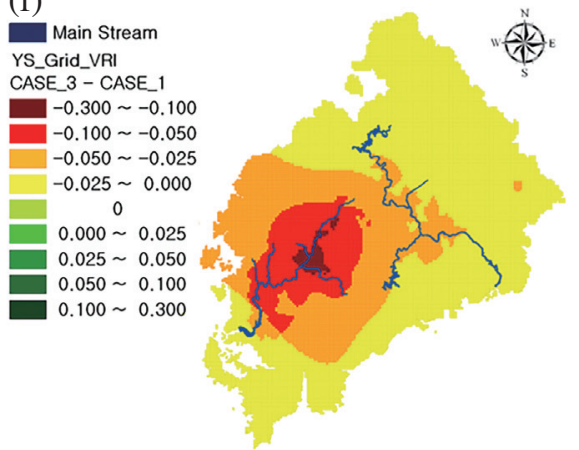

Fig. 7. Vulnerability-resilience index map of the Youngsan River basin for the four cases (a - d): case 1 (w/o restorations, w/o climate change), case 2 (w/ restorations, w/o climate change), case 3 (w/o restorations, w/ climate change), and case 4 (w/ restorations, w/ climate change); and VRI changes based on the status of the Youngsan River basin $(\mathrm{e}-\mathrm{g})$. 
vulnerable resilience did not notably improve. As shown in Fig. 7e, some grids around the main stream flow of the left river for the most part improved in vulnerable resilience with the inclusion of climate change. When climate change is included, the grids around the main stream were substantially influenced in terms of the VRIs. Additionally, nearly all of the grids worsened, with minimized VRIs after the inclusion of climate change.

\section{CONCLUDING REMARKS}

Diverse changes in water resources are happening (e.g., increasing or decreasing precipitation and stream flow), which can be attributed to changing temperatures and climate. Based on these changes, central and local governments need to recognize the current and future status of water resources in controlling and fulfilling water demands. For the Korean peninsula, two major factors, climate change and the restoration of major watersheds need to be evaluated to increase adaptation capability. This study implemented VRIs using Delphi survey applications for weighting factors on proxy variables based on the opinions of water resources experts. The VRIs were categorized into three sectors - climate exposure, sensitivity, and adaptive capacity - and evaluated for two different conditions. In the Delphi survey, $46 \%$ of the experts (12/26) participated, reaching a consensus was based on increased Kendall's W for exposure. VRIs based on the current environment including consideration of the major watershed restorations presented a positive impact on vulnerability resilience around the main stream area. When including climate change, however, the effects of the restorations were minimized and the impacts of climate change were seen over the entire watershed area. Central and/or local governments should be required to investigate several factors besides the main stream flow because, even after the restorations were completed, vulnerable resilience was seen to decrease. To increase the vulnerability resilience, enforced adaptive capacity (e.g., a highly ranked proxy variable: a hazard mitigation system) should be provided. The Youngsan River basin in particular showed the limitations of vulnerable resilience under current conditions, meaning that the vulnerable resilience of this region still needs to be improved. With regard to acting as a policy reference, the VRIs show potential to act as helpful scientific evidence with the function of weighting factors from the Delphi surveys.

Acknowledgements This research was supported by a grant (NEMA-NH-2011-45) from the Natural Hazard Mitigation Research Group, National Emergency Management Agency of Korea.

\section{REFERENCES}

Balica, S. F., N. G. Wright, and F. van der Meulen, 2012: A flood vulnerability index for coastal cities and its use in assessing climate change impacts. Nat. Hazards, $\mathbf{6 4}$, 73-105, doi: 10.1007/s11069-012-0234-1. [Link]

Brooks, N., W. N. Adger, and P. M. Kelly, 2005: The determinants of vulnerability and adaptive capacity at the national level and the implications for adaptation. Global Environ. Chang., 15, 151-163, doi: 10.1016/j. gloenvcha.2004.12.006. [Link]

Elmer, F., I. Seifert, H. Kreibich, and A. H. Thieken, 2010: A delphi method expert survey to derive standards for flood damage data collection. Risk Anal., 30, 107-124, doi: 10.1111/j.1539-6924.2009.01325.x. [Link]

Eriksen, S. H. and P. M. Kelly, 2007: Developing credible vulnerability indicators for climate adaptation policy assessment. Mitig. Adapt. Strat. Gl., 12, 495-524, doi: 10.1007/s1 1027-006-3460-6. [Link]

Füssel, H. M. and R. J. T. Klein, 2006: Climate change vulnerability assessments: An evolution of conceptual thinking. Clim. Change, 75, 301-329, doi: 10.1007/ s10584-006-0329-3. [Link]

Iglesias, A, E. Lin, and C. Rosenzweig, 1996: Climate change in Asia: A review of the vulnerability and adaptation of crop production. Water Air Soil Pollut., 92, 13-27.

Jung, Y. and M. Choi, 2012: Survey-based approach for hydrological vulnerability indicators due to climate change: Case study of small-scale rivers. J. Am. Water Resour. Assoc., 48, 256-265, doi: 10.1111/j.17521688.2011.00608.x. [Link]

Kasperson, J. X., R. E. Kasperson, B. L. Turner II, W. Hsieh, and A. Schiller, 2002: Vulnerability to global environmental change. In: Diekmann, A., T. Dietz, C. Jaeger, and E. Rosa (Eds.), Human Dimensions of Global Environmental Change, MIT Press, Cambridge, MA.

Kennedy,H. P., 2004: Enhancing Delphi Research: Methods and results. J. Adv. Nurs., 45, 504-511, doi: 10.1046/ j.1365-2648.2003.02933.x. [Link]

Kyoung, M. S., 2010: Assessment of climate change effect on drought frequency based precipitation. Ph.D. Thesis, Inha University, Incheon, Korea, 44-48.

Lim, B., E. Spanger-Siegfried, I. Burton, E. L. Malone, and S. Huq, 2005: Adaptation Policy Frameworks for Climate Change: Developing Strategies, Policies and Measures, Cambridge University Press, USA, 258 pp.

McCarthy, J. J., O. F. Canziani, N. A. Leary, D. J. Dokken, and K. S. White, 2001: Climate Change 2001: Impacts, Adaptation and Vulnerability, Contribution of Working Group II to the Third Assessment Report of the Intergovernmental Panel on Climate Change, Cambridge University Press, Cambridge, UK.

Moss, R. H., A. L. Brenkert, and E. L. Malone, 2001: Vulnerability to climate change: A quantitative approach. Pacific Northwest National Laboratory, United States Department of Energy.

Okoli, C. and S. D. Pawlowski, 2004: The delphi method 
as a research tool: An example, design considerations and applications. Inform. Manag., 42, 15-29, doi: 10.1016/j.im.2003.11.002. [Link]

Parry, M. L., O. F. Canziani, J. P. Palutikof, P. J. van der Linden, and C.E. Hanson, 2007: Climate Change 2007: Impacts, Adaptation and Vulnerability, Contribution of Working Group II to the Fourth Assessment Report of the Intergovernmental Panel on Climate Change, Cambridge University Press, UK, Cambridge, 976 pp.

Rothman, D. S. and J. B. Robinson, 1997: Growing pains: A conceptual framework for considering integrated assessments. Environ. Monit. Assess., 46, 23-43, doi: 10.1023/A:1005779717065. [Link]

Rygel, L., D. O'sullivan, and B. Yarnal, 2006: A method for constructing a social vulnerability index: An application to hurricane storm surges in a developed country.
Mitig. Adapt. Strat. Gl., 11, 741-764, doi: 10.1007/ s11027-006-0265-6. [Link]

Taylor, J. G. and S. D. Ryder, 2003: Use of the delphi method in resolving complex water resources issues. $J$. Am. Water Resour. Assoc., 39, 183-189, doi: 10.1111/ j.1752-1688.2003.tb01570.x. [Link]

United Nations Development Programme (UNDP), 2006: Human Development Report 2006: Beyond Scarcity: Power, Poverty and the Global Water Crisis, Palgrave Macmillan,388 pp.

Wicklein, R. C., 1993: Identifying critical issues and problems in technology education using a Modified-Delphi Technique. J. Tech. Educ., 5, 54- 71.

Yoo, G. Y. and I. A. Kim, 2008: Development and application of a climate change vulnerability index. Report05, Korea Environment Institute. (in Korean) 